\section{B A Institute of \\ YK Business Administration \\ 六下 \\ Karachi \\ Leadership and Ideas for Tomorrow}

Article 4

Volume 12 Issue 1

January-June 2017

$1-1-2017$

\title{
Sampling of imported refined oil: A need to clarify the legal framework for oil marketing companies
}

Mohammmad Sohaib Saleem

Institute of Business Administration, Karachi, Pakistan

Follow this and additional works at: https://ir.iba.edu.pk/businessreview

Part of the Business Organizations Law Commons

\section{cc) (7)}

This work is licensed under a Creative Commons Attribution 4.0 International License.

\section{Recommended Citation}

Saleem, M. S. (2017). Sampling of imported refined oil: A need to clarify the legal framework for oil marketing companies. Business Review, 12(1), 59-70. Retrieved from https://doi.org/10.54784/ 1990-6587.1049 


\title{
Sampling of imported refined oil: A need to clarify the legal framework for oil marketing companies
}

\author{
Mohammmad Sohaib Saleem
}

\begin{abstract}
This paper examines whether the legal framework for oil cargo sampling in Pakistan allows for resampling. We find that the laws lack uniformity and clarity and hinder the smooth import of oil into the country. An examination of the pertinent laws and precedents reveal that resampling and retesting of imported oil cargoes is allowed under Pakistani Law.
\end{abstract}

Keywords Imported refined oil · Pakistani law · Sampling · Retained sample

\section{Introduction}

Pakistan relies heavily on oil imports. As per the Pakistan Oil Report (20152016) issued by Oil Companies Advisory Committee (OCAC), in the year 20152016, 8.45 million tonnes of crude oil was imported into Pakistan amounting to a value of US\$2,758.18 million. Crude oil is refined in Pakistan by local refineries such as, Byco Petroleum Pakistan Limited (BPPL), Pak Arab Refinery Company Limited (PARCO), Pakistan Refinery Limited (PRL) and National Refinery Limited (NRL). The refined products mainly include, Furnace Oil (FO), Naptha, High Speed Diesel (HSD), Motor-gasoline (MS) and Kerosene.

The demand for refined oil products has been steadily increasing over the years. Also, the fact that much of Pakistan's power generation is dependent on oil has led to an ever increasing demand for Furnace Oil, particularly High Sulphur Furnace Oil (HSFO). Therefore, since the mid-nineties, huge quantities of refined oil products such as HSFO, Low Sulphur Furnace Oil (LSFO), MS, HSD and Jet Fuel (JP-1) are being imported into Pakistan. The Oil Marketing Companies (OMCs), including Pakistan State Oil, Hascol, Shell Pakistan Limited and Total Pakistan Limited under the terms of their license are responsible for import, storage and distribution of refined oil into Pakistan. In the year 20152016, 13.7 million tonnes of refined oil products were imported into Pakistan.

Mohammmad Sohaib Saleem

Institute of Business Administration, University Road, Karachi-Pakistan

E-mail: sohaibsaleem@iba.edu.pk

(C)Saleem, S. M. 2017 
A breakdown of the same is provided in table 1.

Table 1: Oil Import in year 2015-2016

\begin{tabular}{lrr}
\hline Product & Quantity (M. Tons) & C\&F Value (Million US\$) \\
\hline 100/LL & 1044 & 1.48 \\
JP-1 & 110271 & 52.65 \\
MOGAS & 4251563 & 2098 \\
HSD & 3064764 & 1217.64 \\
Furnace Oil & 6228427 & 1407.2 \\
Total Product & 13656069 & 4776.97 \\
\hline
\end{tabular}

The quality of the oil being imported has to be as per the notified specifications issued by the Oil and Gas Regulatory Authority (OGRA). These specifications are mainly those being used by Pakistan State Oil and are found attached to the tender documents being issued by them for the international procurement of oil.

The issue however, is not in the specifications but in ensuring the specifications are met at every stage of the oil import process. As an industry practice oil cargo is tested at the port of loading (load port) before the vessel is loaded with oil. The oil cargo is also tested after loading on to the vessel at the load port. However, the most important testing is done before the discharge of oil cargo from the vessel at the port of discharge (discharge port), which in case of Pakistan is either the Bin Qasim port or the Keamari port in Karachi.

The oil sampling activity at the discharge port is the most important activity in the entire oil import process. The sample from the imported oil cargo is drawn by an independent surveyor (a representative of a cargo surveying firm) under the supervision of the officials of the Hydrocarbon Development Institute of Pakistan (HDIP). The sample is then taken for testing to the HDIP laboratory and a testing certificate, certifying the quality is issued. This certificate by the HDIP is a requirement for discharging oil cargo in Pakistan.

This sampling and testing activity is a regulated activity for which different laws, rules and policies have been made. However, recently, the said laws, rules and policies have caused a lot of confusion due to lack of clarity and uniformity. OMCs being the importers and the international oil companies being the exporters have suffered due to the ambiguous legal framework applicable on the oil sampling and testing activity at the discharge port. The major concern is the alleged prohibition of drawing a fresh sample of oil from the vessel in the case when the first sample has failed the quality test. The HDIP has refused to test a fresh sample of oil from the same cargo on the pretext of such legal prohibition and as a consequence there have been instances when the oil cargo has not been discharged due to the lack of quality certification from the HDIP.

This has important ramifications for the oil industry of Pakistan. Although not a frequent occurrence, the assumed prohibition on fresh sampling resulting in the non-discharge of imported oil cargoes has caused problems such as, precariously low stock levels, increased demurrage payments, unnecessary litigation, delayed payments and reluctance of international oil companies to export 


\section{to Pakistan.}

Following are two instances where the first oil sample failed the test and a fresh sample was not drawn (or drawn after considerable delay / after court order thereby incurring demurrages) from the vessel.

\subsection{HSFO cargo on board MT Beech-4}

In 2014, HSFO imported by PSO which was on board the vessel MT Beech-4 encountered an issue with HDIP testing. The first samples were tested and did not match the required specifications. What followed was a deadlock situation where the vessel was stuck at the port for several days. Later an order of the court was issued asking for testing of a fresh sample and subsequent discharge of oil from the vessel.

\subsection{LSFO cargo on board MT Quetta}

In 2015 around 69000 metric tonnes of LSFO imported by PSO for Kot Addu Power Company (KAPCO) met a similar fate as mentioned above. The vessel MT Quetta was loaded with the LSFO cargo at Fujairah (UAE) after passing all testing and sampling processes. When the vessel arrived at the Keamari port Karachi (the discharge port) an issue occurred with the HDIP testing. This matter was also eventually resolved after obtaining orders from the court for fresh sampling and testing.

In light of the above and many other instances involving similar issues with testing, there is a need to scrutinize and analyse the various relevant laws, rules, cases and policies to discern the correct legal way forward in a situation when the first sample of oil fails the testing at the discharge port.

\section{Why is it important to test fresh samples rather than retained samples?}

Before we undertake a deeper analysis of the issues, the need for using fresh samples must be understood from a technical and practical point of view. Oil products like HSFO, LSFO, Mogas, which are regularly imported in Pakistan as per the country specifications are not straight-run refinery products. These products are blended at loading ports by the suppliers to meet the Pakistani specifications and then they are loaded on vessels destined to Pakistan. Before the product is loaded on to the vessel it is tested by independent international laboratories verifying the quality of the product as per the specifications. These oil vessels are made up of several small and big tanks which are specially equipped for oil storage and transportation. The sampling procedure at both the load port and the discharge port involves making a composite sample made up of samples from the upper part, middle part and lower part of each ship tank, commonly known as UML samples. This means that several sets of 
samples from each ship tank are taken, one set becomes part of the first composite sample and the second set becomes part of the second composite sample i.e. the retained sample. Oil products are blended and non-homogenous and undergo layering during transit. Therefore, at times when a sample is drawn from a vessel's tanks for testing at the discharge port the sample is not a true representative sample of the loaded cargo and variations occur in between the test reports of testing done at the load port and the discharge port.

For example, although the three samples may have been taken from the same tank they could have different test results because the person who made up the three samples from the bulk oil failed to thoroughly stir/shake/blend the tank before he poured oil into the three sample bottles. It is possible that if not properly blended the, heavier components of the fuel like catalytic fines, water and other solids will not be proportional in all three samples, (source International Bunker Industry Association). The sampling activity is prone to human errors and at times a slight error / carelessness in drawing the samples on part of the surveyor may result in huge variations in the product test reports. As both the first and second (retained) samples are drawn simultaneously the testing of the second (retained) sample in case of a dispute would yield the same or very similar results. Therefore, once the incorrect samples are drawn at the discharge port and they subsequently fail the quality tests there is no process or guideline to discharge the cargo which remains stranded at high sea presenting numerous costs and risks. Therefore, the only thing which can settle the dispute conclusively is the drawing of fresh samples ideally by a different surveyor.

\section{Roles and relationship of OGRA, the Ministry of Petroleum and Natural Resources (MoP\&NR) and HDIP in the context of oil testing and sampling}

\subsection{OGRA}

OGRA was established under the OGRA Ordinance, in the year 2002. The basic role of OGRA is to grant a license for conducting regulated activities in Pakistan relating to oil and gas. Section 23 (3) of the Ordinance provides that unless a license is obtained from OGRA no person can construct or operate any refinery, blending plant, storage facility, pipeline and cannot undertake any marketing activity for refined oil products.

Section $41 \& 42$ of the Ordinance respectively provide OGRA with the power to make rules and regulations. Section 6 of the Ordinance outlines the powers and functions of OGRA. Amongst other things OGRA has the authority to enforce federally notified standards and specifications for refined oil products.

\subsection{Ministry of Petroleum \& Natural Resources (MoP\&NR)}

Petroleum \& Natural Resources Division is a Ministry of the Federal Government of Pakistan and was created in April 1977. Prior to that, Petroleum and 
Natural Resources was part of the Ministry of Fuel, Power and Natural Resources. Its mission is to ensure the availability and security of a sustainable supply of oil and gas for economic development and other strategic requirements of Pakistan and to coordinate the development of energy and mineral resources. The Federal Government acts through the MoP\&NR when issuing directives to OGRA. The Directorate General for Oil ("DG Oil") which is a section of MoP\&NR is responsible for matters pertaining to oil.

\subsection{HDIP}

HDIP is an autonomous body of the MoP\&NR established in 1975 under a resolution of the Federal Government. It was re-established under the Hydrocarbon Development Institute of Pakistan Act 2006 ("HDIP Act"). The Chairman of the Board of Governors of HDIP is the Minister of Petroleum and Natural Resources. The majority of members of the Board of Governors of HDIP are also from the MoP\&NR. Furthermore, the Director General of HDIP reports to the MoP\&NR.

The purpose of HDIP as per the HDIP Act is to undertake, promote and guide scientific research and development in the field of hydrocarbons and for matters connected therewith or ancillary thereto. Amongst other things the HDIP Act section 4 states (")(n) To perform such function for the Government and the regulators in hydrocarbon sector as the Government or the regulators may assign to it from time to time".

\subsection{The relationship between OGRA, MoP\&NR and HDIP}

In order to better understand the linkages between OGRA, MoP\&NR and HDIP we need to understand section 21 of the Ordinance. In this section the Federal Government has been empowered to issue Policy Guidelines to OGRA on matters of policy and OGRA is required to comply with these guidelines in the exercise of its powers. Amongst other things, subsection 2(c) of Section 21 of the Ordinance authorizes the Federal Government to issue Policy Guidelines relating to standards and specifications for refined oil products.

In the light of the above, the role of MoP\&NR acting as an arm of the Federal Government is to issue Policy Guidelines to OGRA. Both MoP\&NR and OGRA being the Government and the regulator respectively may assign any function to HDIP (as stated in HDIP Act).

\section{The laws governing sampling of oil cargo in Pakistan}

Listed below are the laws (including rules and policies) currently applicable to testing and sampling of imported oil cargo.

- Petroleum Act 1934 (Chapter II, sections 14 to 22)

- Petroleum Rules 1937 (Chapter IX, rules 153 to 163) 
M. S. Saleem

- Petroleum (Refining, Blending and Marketing) Rules, 1971 (Part VI, rules 36 to 38$)$

- Policy Guidelines issued by MoP\&NR circulated by OGRA vide its letter (OGRA (Oil) 19-7-(5)/2006), dated 20th April 2007

\section{Is re-sampling of oil cargo prohibited under the Pakistani law?}

As stated above, the laws lack clarity and therefore the answer to the question is complex. As a matter of law (since Pakistan is a common law country), it is clear that Acts are superior to Rules and Policies.

A rule or a bye-law made under a statute cannot, unless there are express indications in the statute itself, override the provisions of other statutes or the general law as reported in Burrakar Coal Co. Ltd. v Labor Appellate Tribunal Air 1958 Cal. 226, 228; and Co-operative Society of Kottapalli v Registrar Cooperative Societies AIR 1966 Andh Pra 160. Details regarding why policies are subordinate to Acts and rules are discussed below. The Petroleum Act 1934 (Act 1934), clearly allows for fresh samples (re-sampling). Section 20 (1) \& (2) of the Act 1934 states:

\subsection{Right to require re-test}

1. The owner of any petroleum, or his agent, who is dissatisfied with the result of the test of the petroleum may, within seven days from the date on which he received intimation of the result of the test, apply to the officer empowered under section 14 to have fresh samples of the petroleum taken and tested.

2. On such application and on payment of the prescribed fee, fresh samples of the petroleum shall be taken in the presence of such owner or agent or person deputed by him, and shall be tested in the presence of such owner or agent or person deputed by him.

It may be argued that the above section does not discuss sampling and testing of cargo imported by sea and samples obtained from a ship. However, the Petroleum Rules 1937 (Rules 1937), which have been made pursuant to the Act 1934, state at length the testing and sampling procedures for cargoes imported by sea.

Rules 1937 have been made by the Federal Government pursuant to the powers conferred by section 4, subsection (2) of section 5, sub-section (2) of section 14, sections 21 and 24 and sub-section (1) of section 29 of the Petroleum Act 1934, read with section 22 of the General Clauses Act 1897. Therefore, it is clear that Rules 1937 are enforceable by law.

It is evident that the Act 1934 and the Rules 1937 have not been repealed as both are still referred to and relied on by OGRA. Recently OGRA issued a notification (OGRA-Oil 19-9 (27)/08 dated 5th October 2015) citing both the Act 1934 and Rules 1937. Also, section 43 of the OGRA Ordinance (discussed in detail below) in my opinion acts as a saving provision for the Act 1934 and 
the Rules 1937. Furthermore, it was once contended by OGRA that the Act 1934 and Rules 1937 have been overridden by the OGRA Ordinance. However, the Supreme Court of Pakistan in a recent case, (HRC No.20107-G/2013) seems to disagree with this point of view, as in its order it directed one of the parties to exercise the powers conferred to it in the Rules 1937.

Amongst other provisions, rules 153 (3), 155 and 156 of Rules 1937 specifically talk about imported cargo and obtaining samples from a ships tank(s). Of particular interest is the fact that the Rules 1937 refer to section 20 of the Act 1934 in rule 163 and expressly talk about re-testing of samples and refund of fee in case of erroneous testing. As section 20 of the Act 1934 talks about taking fresh samples and re-testing, it is my opinion that the taking of fresh samples i.e. re-sampling is allowed.

It may be argued that Act 1934 is restricted to testing imported petroleum for determining whether it is dangerous, non-dangerous or heavy by reference to its flash point (as stated in Chapter II of the Act) and no other quality parameters which are included in the specifications such as metal content, water content and viscosity have been discussed.

However what needs to be appreciated here is the fact that Act 1934 is the only Act of law which covers the import of oil cargoes. Furthermore, it has a broader scope and should not be restricted to the testing of flash point only. Whilst it should be noted, that at the time of the enactment of the Act 1934, flash point was the only and most important quality parameter, the Act 1934 gives powers to the Central and Federal Government in relation to testing of petroleum, which go beyond simply testing the flash point. The testing laboratories still include Flash Point as a quality parameter along with other later additions while testing a sample of oil cargo. So if the Act 1934 and the Rules 1937 are clear about fresh sampling, then where and how does the confusion arise? For an explanation of this it is necessary to refer to the Petroleum (Refining, Blending and Marketing) Rules, 1971 (Rules 1971).

Rule 38 of the Rules 1971 provides the procedure for sampling and testing. In elaborating the procedure it explains that an officer should take samples of the petroleum product in two separate containers and seal them both with his own seal and if required the petroleum owner's seal as well. The officer is then required to retain one of the containers with himself and forward the other to an authorised laboratory for testing. Rules 38 (3) and (4) of the Rules 1971 address the issue of any dispute arising from the tests conducted by the laboratory. They provide for the re-testing of the sample retained by the officer with himself. This second testing (testing of the retained sample) is to be the final testing for addressing any dispute and shall not be called into question.

Therefore, in light of the above, Rules 1971 do not talk about fresh samples but rather they talk about what is known in the oil industry as retained sample(s). Retained sample became the name of the second set of samples which a laboratory would test in case the results of the first sample did not meet the specified standards. This saved the time consuming exercise of drawing samples again. Therefore, this provided a safeguard against erroneous testing by the laboratory. However, since both the first and the second samples (i.e. the retained sample) are drawn together, no safeguard is available against an erroneous sam- 
ple taking exercise by a surveyor.

The predominant practice when sampling an imported oil cargo on board a ship, is to have a composite sample made up of samples from the upper part, middle part and lower part of each ship tank, commonly known as UML samples. This means that several sets of samples from each ship tank are taken, one set becomes part of the first composite sample and the second set becomes part of the second composite sample i.e. retained sample. Therefore, the possibility of erroneous sampling is far greater when samples of imported cargo on board a ship are taken. For example, a surveyor may not correctly draw samples from the upper, middle or lower part of a $\operatorname{tank}(\mathrm{s})$, or may just draw all the sample from one part and/or one tank (out of the many ship tanks) or may use improper containers/seals for the samples. The Rules 1971 do not cover such practice nor provide any recourse for incorrect sampling. Therefore, Rules 1971 were never applied in the oil industry in cases where samples were drawn from ships bringing in imported cargoes. Also, the Rules 1971 were made in exercise of the powers conferred by section 2 of the Regulation of Mines and Oil-Fields and Mineral Development (Government Control) Act 1948 (Act 1948).

The Act 1948, unlike the Act 1934, does not discuss oil sampling and testing and deals with local regulation of oil and oil fields. The Act 1948 as per section 2 pertains to matters such as grant renewal of oil exploration licences, leases, concessions, determination of rates, royalties and prices of minerals and mineral oil and control of production, storage and distribution of minerals and mineral oils.

Since Act 1948, does not discuss the import of oil or refined oil and/or sampling and testing of imported oil cargoes, it will be ultra vires of the Act 1948 to give effect to the Rules 1971, to have an impact on oil cargo imported by sea. Rules have to be consistent with the statute under which they are framed and with all that is deemed to be incorporated in the statute (Province of East Pakistan v Noor Ahmed PLD 1964 SC 451). The rules must conform strictly to the statute passed by the legislature (M/s Mehraj Flour Mills v Provincial Government 2001 SCMR 1806).

Furthermore, Rules 1971 cover operations of refining, blending and marketing. All these operations are inland operations and hardly involve the intricate details of drawing samples from various tanks of a ship and making a UML sample. The Rules 1971 only briefly discuss import specifications in rule 11 (under Part II which deals with refining and not marketing), and lack the details regarding oil import procedures (including drawing samples from ship), when compared to Rules 1937. Rule 34 of Rules 1971 allows for any authorized person to enter and inspect any refinery, a blending plant or a marketing company and check the enforcement of the Rules 1971. Rule 36 of Rules 1971 further provides that the authorised officer may take samples of a petroleum product from a refinery, blending plant (reclamation plant), marketing company, installation, storage, depot or distribution outlet. In light of the above rules, it is evident that testing and sampling defined in Rules 1971 is of a product in possession/ownership of a refinery, blending plant (reclamation plant), marketing company, installation, storage, depot or distribution outlet.

The Rules 1971 do not talk about product on board a ship which is yet to 
be taken in possession/ownership by the OMC. Therefore, in my opinion, Rules 1971 are not applicable to that dispute which arises out of a sampling issue of a cargo which at the time of sampling is legally owned and in possession of Mena (the supplier), which under the Rules 1971 is not a refinery, blending plant (reclamation plant), marketing company, installation, storage, depot or distribution outlet. Also, nowhere do the Rules 1971 discuss cargo quality disputes between an OMC (oil importer) and an oil supplier. In my opinion the legislative intent of the Rules 1971 is clear from its enabling statute i.e. the Act 1948, which does not mention import of oil and/or testing procedures. The whole scheme of the Rules 1971 as far as an OMC is concerned is to regulate marketing and distribution activities. Conversely, the regulation of imports is clearly within the scope of the Act 1934 and Rules 1937. It should also be noted here that new Rules have been drafted and issued by OGRA, which are called The Petroleum (Refining, Blending and Marketing) Rules, 2016 (Rules 2016). However, currently a stay order obtained by OCAC on the implementation of the Rules 2016 from the Islamabad High Court is in place and therefore the Rules 2016 are not being followed by the oil industry.

The Rules 2016 deal with imported cargoes under Rule 42 and expressly state that imported cargoes are subject to quality clearance from the approved laboratory in accordance with the procedure and testing charges as prescribed by the Authority from time to time. Here, again it is evident that the sampling and testing procedures provided for in the rules (even in the new Rules 2016) are not to be applied when drawing samples of imported cargo from a ship. However, the foremost reason for the refusal of fresh sampling (re-sampling) by the HDIP arises from the application of Policy Guidelines issued by MoP\&NR circulated by OGRA vide its letter (OGRA (Oil) 19-7-(5)/2006), dated 20th April 2007, ("Policy 2007"). The Policy 2007 only talks about testing of retained sample in case of a quality dispute. The relevant sections of the Policy 2007 are reproduced below:(")(ii) The quality of the products for importers including OMCs and industrial consumers shall be tested by HDIP Laboratory Karachi prior to unloading. Samples of products for quality analysis will be done by OCAC approved surveyors in presence of HDIP representatives as per prescribed procedure. The same procedure will also apply for HSD imports by OMCs and bulk consumers approved by the Ministry. (iii) In case of quality dispute, second retained sample will be tested by HDIP in the presence of nominated representative of the importer. Test result of the second sample will be final and binding".

As can be seen above, the Policy 2007 only talks about testing of a "second retained" sample in case of a quality dispute. The policy is silent about drawing fresh samples. It is further stated therein that the test result of the second sample will be "final and binding". Therefore, it is implied that re-sampling is not allowed as per the Policy 2007. 
5.2 The important question then is does the Policy 2007 override the Rules 1937 and the Rules 1971 ?

In my opinion, Policy 2007 has been issued by MoP\&NR pursuant to section 21 of Oil \& Gas Regulatory Authority Ordinance 2002 (Ordinance) and hence has the force of law. However, section 21 does cater to a conflict situation between the rules and policy guidelines. Section 21 of the Ordinance provides that the Federal Government, i.e. MoP\&NR can issue policy guidelines to OGRA. However, such policy guidelines cannot be inconsistent with the provisions of the Ordinance or the rules issued under it.

Section 43 (2) of the Ordinance provides that the Ordinance is to override other laws however it shall not impact or be deemed to affect amongst other things any rules and regulations issued under any law repealed or amended by the Ordinance. Furthermore, the said rules and regulations shall continue to be in force and have effect as if they were issued under the Ordinance. In light of this, the Rules 1937 and Rules 1971 are deemed to have been issued under the Ordinance and hence the Policy 2007 cannot be inconsistent with any of them.

Additionally, Section 43 (1) of the Ordinance provides that the Ordinance, rules and regulations, and any licenses issued under the Ordinance shall override and have effect notwithstanding anything to the contrary contained in any other law. However, this provision does not state that it includes any Policy Guidelines and hence the Policy 2007 cannot be said to have an overriding effect. Finally, it is to be noted here that on page 2 of the Policy 2007 it is stated that HDIP was to lay down the Standard Operating Procedures in the light of the Policy 2007 within 7 days under intimation to OGRA and in coordination with the OMCs, however, this apparently was never done and therefore creates ambiguity in the implementation and enforcement of the Policy 2007.

\subsection{What is the opinion of the court?}

In the two Constitutional Petitions which were filed in the case of HSFO cargo on board the vessel MT Beech-4 (CP 1557 of 2014 in the Sindh High Court at Karachi, PNSC v Federation of Pakistan, PSO \& others) and LSFO cargo on board the vessel MT Quetta (CP 1824 of 2015 in the Sindh High Court at Karachi, PNSC v Federation of Pakistan, PSO \& others), the Court passed orders to proceed with taking fresh samples and testing the same to ascertain quality. The Court even ordered to discharge the oil in the shore tanks and then take fresh samples for conducting tests for quality, which clearly shows that the Court understands the urgency and significance of the matter and how lack of clarity in the law was causing delays. Hence it is evident that the prohibition of resampling as provided in the Policy 2007 was completely disregarded.

\section{What are the international best practices?}

According to American Petroleum Institute (API) which is a global leader in setting standards in the oil industry, there is no limit to taking the number of 
retained samples or re-samples. As per Recommended Practice on Light Product Quality Terminal Operations section 2.4 in case of complaints, disputes or incidents retained samples are often tested to establish the actual product quality and the presence of any cause of failure at that point in the supply chain. However, APIs definition of the retained sample is not limited to the retained sample drawn at the discharge port (and which is the one to be tested in case of dispute under the Policy 2007) but also the retained sample kept with the supplier at the load port, which of course would be as per the approved specifications, since loading of cargo would have only commenced if the sample had passed the tests.

As per API retained samples may be taken and stored at a number of points in the supply chain including the refinery finished product tank, entry into 3rd party pipeline, jetty when loading a ship or barge, barge when bunkering a ship, terminal tank/pipeline on receipt of the product into the terminal and from trucks before delivery to the customer. For all points in the supply chain, retained samples should be taken in accordance with ASTM, API MPMS standards or international equivalent. Furthermore, according to API the product can only be released for shipment or pipeline delivery when it is according to the specification defined by the contractual agreement and/or regulatory requirements. When the product is found to be off-test it should be immediately re-sampled and re-tested. It should be noted here that no limits have been prescribed here by API on the number of times of re-sampling/re-testing. In their guidelines they recommend re-sampling even on the basis of suspicion that the sample drawn is not representative of the bulk oil cargo.

\section{Conclusion}

In my opinion, cargo re-sampling is allowed under the Pakistani Law as it is provided for in the Petroleum Act of 1934. Additionally, the Petroleum Rules 1937 expressly state the sampling procedures for drawing samples from imported cargo on board a ship. The Pakistan Petroleum (Refining, Blending and Marketing) Rules, 1971 are not applicable to sampling of oil on board a ship. In my opinion, the rules are only meant to be applied when sampling oil which is already in the custody of a company/party onshore in Pakistan. This is further supported by the fact that the sample of oil is to be taken from an inland storage installation such as a depot, refinery, storage tank etc. The Policy 2007 is in conflict with the Petroleum Act 1934, it is an incomplete policy as no Standard Operating Procedure for sampling was made pursuant to it by HDIP in coordination with OMCs and therefore the Policy 2007 is of no legal consequence. Finally, in two orders (in CP 1557 of 2014 and CP 1824 of 2015), the Sindh High Court has allowed for re-sampling and re-testing of imported cargoes.

\section{References}

Petroleum Act 1934;

Petroleum Rules 1937;

Business Review: (2017) 12(2): 59-70 
Petroleum (Refining, Blending and Marketing) Rules, 1971;

Policy Guidelines issued by MoP\&NR circulated by OGRA vide its letter (OGRA (Oil) 19-7-(5)/2006), dated 20th April 2007;

Regulation of Mines and Oil-Fields and Mineral Development (Government Control) Act 1948;

Oil \& Gas Regulatory Authority Ordinance 2002;

Hydrocarbon Development Institute of Pakistan Act 2006;

Pakistan State Oil Tender specifications for refined Oil

Pakistan Oil Report (2015-2016) issued by Oil Companies Advisory Committee (OCAC).

CP 1557 of 2014 in the Sindh High Court at Karachi (PNSC v Federation of Pakistan, PSO \& others)

CP 1824 of 2015 in the Sindh High Court at Karachi (PNSC v Federation of Pakistan, PSO \& others)

Burrakar Coal Co. Ltd. v Labor Appellate Tribunal Air 1958 Cal. 226, 228;

Co-operative Society of Kottapalli v Registrar Co-operative Societies AIR 1966 Andh Pra 160.

Province of East Pakistan v Noor Ahmed PLD 1964 SC 451).

M/s Mehraj Flour Mills v Provincial Government 2001 SCMR 1806

OGRAs notification OGRA-Oil 19-9 (27)/08 dated 5th October 2015

Supreme Court of Pakistan HRC No.20107-G/2013

Recommended Practice on Light Product Quality Terminal Operations issued by American Petroleum Institute 